\title{
The Judas Iscariot Syndrome and Its Implication for Accounting Educators
}

\author{
Williams Kwasi Peprah ${ }^{1}$, Josephine Ganu ${ }^{2}$, Daniel Dei ${ }^{1}$,Edwin A. Balila ${ }^{3}$, Jolly S. Balila ${ }^{3}$ \& Glenda Joy B. Lopez ${ }^{3}$ \\ ${ }^{1}$ Valley View University, School of Business, Accra, Ghana \\ ${ }^{2}$ Adventist University of Africa, Nairobi, Kenya \\ ${ }^{3}$ Adventist University of the Philippines, Silang Cavite, Philippines \\ Correspondence: Williams Kwasi Peprah, Valley View University, School of Business, Accra, Ghana.
}

Received: May 12, 2020

Accepted: June 16, 2020

Available online: July 22, 2020

doi:10.11114/afa.v6i2.4941

URL: https://doi.org/10.11114/afa.v6i2.4941

\begin{abstract}
The study is qualitative and applied the appreciative inquiry approach to address the "Judas Iscariot syndrome" of misappropriation and wrong assumptions among accountants and treasurers. It is believed that Seventh-day Adventist universities integrate faith and learning in their educational curriculum to cause a behavioral change. There seems to be a gap between knowledge, values, and the practice of accounting and financial management. From the biblical perspective, Judas Iscariot was the treasurer among the twelve disciples of Jesus Christ, but he was said to be a thief (see John 12:4-6). This study utilized a semi-structured, self-developed, open-ended questions in interviewing ten accounting educators at Valley View University, Ghana from the Oyibi and Techiman campuses and based on the triangulation method and the 5-D cycle approach of appreciative inquiry (Define, Discover, Dream, Design, and Delivery). The study revealed that in order to generate positive change, self-discipline, truthfulness, and conscience to duty must be inculcated into the current accounting education to make the student dream to have contentment. The achievement of contentment is based on a design of biblical and ethical discussion, sharing of examples and personal experiences, truth writing and telling, and audiovisual presentation. The study recommends that accounting educators must live an exemplary life, mentor students, use ethical simulations and debates to instill self-discipline, truthfulness, and conscience to duty. A roadmap of Christian Behavior Change for Accounting Educators is developed.
\end{abstract}

Keywords: self-discipline, truth, conscience to duty, accounting educators, contentment

\section{Introduction}

The profession of accountancy and treasury is one of the esteemed and challenging jobs in the world. It seems that all activities, operations, and the crucial decisions in any organization have a monetary value which is disbursed by treasurers and recorded by accountants. Regarding their training, both the accountant and the treasurer, are usually educated in the same program at the tertiary level. While the treasurer manages the finances of the firm, the accountant keeps the records of the books. However, in some firms, one person plays these roles, and this justifies why their education is mostly the same. Thus, in this study, both the accountant and the treasurer are used synonymously.

These professions have suffered blame for most of the misappropriations in businesses and the collapse of giant corporations. In recounting Enron's scandal and others, the role of accountants and treasurers were significantly mentioned as the main culprits (Yigit, 2013). A report issued by Crowe Clark Whitehill and the Centre for Counter Fraud Studies (2017) has noted that the financial cost of fraud has reached $£ 3$ trillion or $7 \%$ on an annual expenditure of companies. Sweet (2018) opines that the role of accountancy in these misappropriations, which are on the increase, could be attributed to social and technological factors. Social factors consist of a greater individualization where ethics and morals are erased. The technological aspect relates to the processes, controls, and computerizations of transactions that have limited the behavioral study in fraud.

Deducing from the fraud diamond theory, Peprah (2018) investigated the motivation for the high increase in misappropriation via ranking of the elements among accountants. The study revealed that the capability influence on the other aspects of opportunity, rationalization, and pressure was very significant to the investigation of fraud. Capability here implies the knowledge, skills, and experience (Wolfe \& Hermanson, 2004; Peprah \& Ganu, 2018) obtained through the education of the accountant.

In considering these factors mentioned by Sweet (2018) and Peprah (2018) and juxtaposing them together, there seems 
to be a gap between knowledge, values, and the practice of accounting and financial management. From the biblical perspective, Judas Iscariot was the treasurer among the twelve disciples of Jesus Christ, but he was said to be a thief (see John 12:4-6). Although he got the best education from Jesus Christ, unfortunately, his values and practices were unchanged and questionable. There is strong biblical evidence in support of the existence of Judas Iscariot. Mainly found in the biblical books of Matthew 26: 14-16; 27:1-10, Mark 13:13-19; 14: 10-21, Luke 6; 22, John 12:1-7; 13:18-30, and the Acts of the Apostles 1:15-26, Judas Iscariot is presented as one of the disciples of Jesus. He is famous for betraying Jesus with a kiss for 30 pieces of silver (Matthew 26:15). Judas Iscariot 'carried away' some of the sums to satisfy his interest. The tense of the word ebastazen meaning "to lift," suggest a continuous act of fraud.

As inferred by Pipim (2018), the high corruption in developing countries involves religious individuals who are dominantly Christians. This opinion, though debatable, carries a sense of blame on the kind of educational training provided to accounting students during the period of their education. Although several factors may contribute to the lapses of moral judgment of accounting professionals, moral education is critical. Thus, it is at the university that accounting educators develop their capabilities. Therefore, this paper seeks to examine how Seventh-day Adventist educational institutions approach accounting education to help reduce the "Judas Iscariot Syndrome" of misappropriation and wrong assumptions in financial matters. Further, Appiah and Wa-Mbaleka (2015) affirm in their study that Seventh-day Adventist universities integrate faith and learning in their educational curriculum.

White (1903) has provided the qualities of professionals the world wants, which accounting educators must embody. These qualities include but are not limited to accountants and treasurers who cannot be bought or sold, professionals who are genuine and honest to duty, and will always stand for the right (White,1903). These character elements should not be as a result of an accident, special favor, or providence but self-discipline attained through Christian education. These characteristics are behavioral attributes expected of Christian professionals.

A study by Tin, Agustina, and Meyliana (2017) accessed behavioral accounting topics for the past ten years and concluded the following: "the strategy/method to alter human behavior $(29.75 \%)$; the handling of human emotion can affect the subject's behavior (27.27\%) and the effect of the accounting system with human behavior (13.22\%)" (p. 1) was the main issue discussed. These behavior accounting studies did not address the core of what kind of training to give but examined how it affects the human resource requirement needs of accounting educators.

The subject of accounting dwells on principles and guidelines as issued by the Financial Standards Accounting Board (FSAB). Mostly referred to as generally accepted accounting principles (GAAP) or International Financial Reporting Standards (IFRS). They are based on principles and assumptions which bring standardization. The principal concepts consist of matching, going concern, full disclosure, cost, and revenue recognition. The assumption approach includes materiality, conservatism, economic entity, monetary unit, and period. The assumption guidelines require the application of subjectivism. The main distinction to the principles and assumptions is based on the application of judgment by the accountant or treasurer on which guidelines to follow. The dichotomy of this individual role of the capable accountant or treasurer is what is causing the "Judas Iscariot syndrome" of misappropriation wrong assumptions. It is upon this premise that accounting education should focus on the self-discipline characteristics mentioned by White (1903). This new form of teaching accounting should inculcate Christian behavioral accounting principles consisting of self-discipline, truth and honesty, conscience to duty, and integrity. These principles must be an integral part of our modern Christian accounting education.

Hagger and Hamilton (2018), studied the impact of self-discipline on academic attainment. Their results showed that self-discipline relates and predicts educational attainment. Self-discipline is an internal discipline that makes people have higher control of their behavior and not ruled by fear of punishment (Walters, 2016). Self-discipline is an individual capability to suppress unwanted behavior but promotes a higher order-goal (Allom, Panetta, Mullan, \& Hagger, 2016). Self-discipline is a teachable behavior. Therefore, it must be inculcated into Christian behavioral accounting education.

According to English and Roy (2015), teaching the truth is as well as writing the truth. The limitation of teaching and writing the facts are concealed in courage, keenness, skill, judgment, and cunning (English \& Roy, 2015; Brecht, 1966). According to Collins (1991), the accounting educator has to speak the truth, teach the truth, call for accountability, societal transformation, and facilitate learning. This makes truth an essential element for Christian behavioral accounting education.

A conscience to duty is expressed in moral knowledge, motivation, and reflection (Wood, n.d). Conscience seeks to explain how knowledge is afforded to the student by the educator. Again, conscience pricks and prods for the right thing to be done by avoiding the wrong option. Conscience also causes thinking on what to do by prioritizing moral considerations. It is conscience that practically holds the accounting educator and the student to duty. 


\section{Method}

The qualitative research method and the appreciative inquiry model are used to address the "Judas Iscariot syndrome." Appreciative inquiry is a strength-based, positive approach in moving people to a shared vision for the future of minimizing the "Judas Iscariot syndrome" of misappropriation and wrong assumptions. Appreciative inquiry is used in behavioral change (Fifolt, \& Lander, 2013). An Interview was conducted with accounting educators at Valley View University, Oyibi, Ghana. To generate the needed information, the researchers utilized a semi-structured, self-developed, open-ended questions in conducting the interview. The study was organized on the 5-D cycle of appreciative inquiry of definition, discovery, dream, design, and destiny/delivery. In order to validate and strengthen the standpoint from various respondents, the triangulation approached is used to compare the responses from ten accounting lecturers from Valley View University, Oyibi, and Techiman campuses.

\section{Results and Discussions}

During the interview section, the accounting educators were asked to provide their understanding based on five schematic questions from the appreciative inquiry approach. They were first asked to give their definition of self-discipline, truth, and conscience to duty. They defined self-discipline as "The ability to control one's feelings and overcome one's weakness or your ability to control yourself without any form of compulsion or one's ability to do what is right consistently." It could be inferred from these definitions that self-discipline is about controls. Thus, it means that accounting educators must focus on how to control themselves on the job.

In considering the definition for truth, the educators stated that truth is "Being in accord with fact and standard or something that is not false or presenting something exactly how it is or saying something as it is. If it is right, you say it and vice versa". The implication for this definition is based on factuality. The indication for accounting education is that it must be taught factually instead of using dummy examples. Educators must use real-life examples. Currently, there are a lot of financial statements available that can be used to teach the students. This will let the student appreciate the use of the accounting standards in providing factual information.

Again, they were asked to define conscience to duty. They resulted by saying it is "Hidden inner compass that guides our lives and moral thought or one's inner sense of what is right or wrong in one's conduct or motive, impelling one towards right action of listening to the inner voice." The inference from these definitions is based on being dutiful. Accounting educators must themselves exhibit the devotion, dedication, faithfulness to their work

In finding out the ways to discover self-discipline, truth, and conscience to duty, the respondents mentioned that in order to discover self-discipline, they must use "natural and logical consequential theory or practical ways that will give a chance for people to decide on their own or sharing stories and videos of disciplined people." When it comes to the discovery of true education and experience, it must be "By demonstrating with examples and role-play or Say the truth always and have Christ in your heart. Again, when it comes to conscience to duty education and experience, it must be "using ethical dilemmas." In a nutshell, the best way to educate and experience self-discipline, truth, and conscience to duty is a combination of ethical theories and dilemmas, practice, stories, and audiovisual presentations based on Christian values.

In assessing the dream for self-discipline, truth, and conscience to duty education among accounting educators, they reported by saying, when it comes to self-discipline, "delay gratification, the resistance of unhealthy temptations and tolerate discomfort or to rightly expense money and account for it consistently." For truth, "disclose all facts and figures with an open and clear conscience or right figures to be shown on financial reports." Lastly, conscience to duty is "instilling a sense of duty to God and man in the accounting profession or should not be manipulated and not maneuver away from the truth. Accountants should not be bought or sold. The idea future for accountants is to be contented. The implication for accounting educators is to teach their students how to be content or be satisfied with their financial means.

The design stage looked at what must be the solution in our current teaching method in accounting education to achieve self-discipline, truth, and conscience to duty. The accounting educators responded by saying that self-discipline "includes ethics and ethical situations in every accounting topic, or the course instructor should demonstrate personal examples, or it should be made a goal throughout all the stages in one's life, daily self-evaluation." Truth changes come from "making bear the consequence of truthfulness and untruthfulness acts or students should be made to know the truth and possibly the consequences of not telling the truth in life or Individuals should accept living a life of truth." Lastly, conscience to duty changes come about when "they change by watching videos, reading books and listening to words that promote conscience to duty or teaching that deals with humanity with empathy and respect in all situations involving third-party resources." The interview has revealed that the current teaching method must include ethics, sharing of personal experiences, discussing the outcome of truth writing, and telling and audiovisual demonstrations.

Finally, the destiny or delivery stage looks at the practical way to implement these recommended changes in accounting 
education in order to affect future behaviors of accountants which are self-discipline, truth, and conscience to duty. "the incorporation of ethical examples and simulations, debates, role-play, discussions, synthesis, the lecturer's exemplary life of self-discipline, truth, and conscience to duty. The exemplary life must be seen in their dressing, time orientation, and delivery of teaching service to the student." It came out that lecturers must exhibit self-discipline, truthfulness, and conscience to duty in their interactions with the accounting students. Teachers should see themselves as role models, mentors, and their students may mimic their character. Therefore, accounting educators' current behaviors will likely influence future accountants.

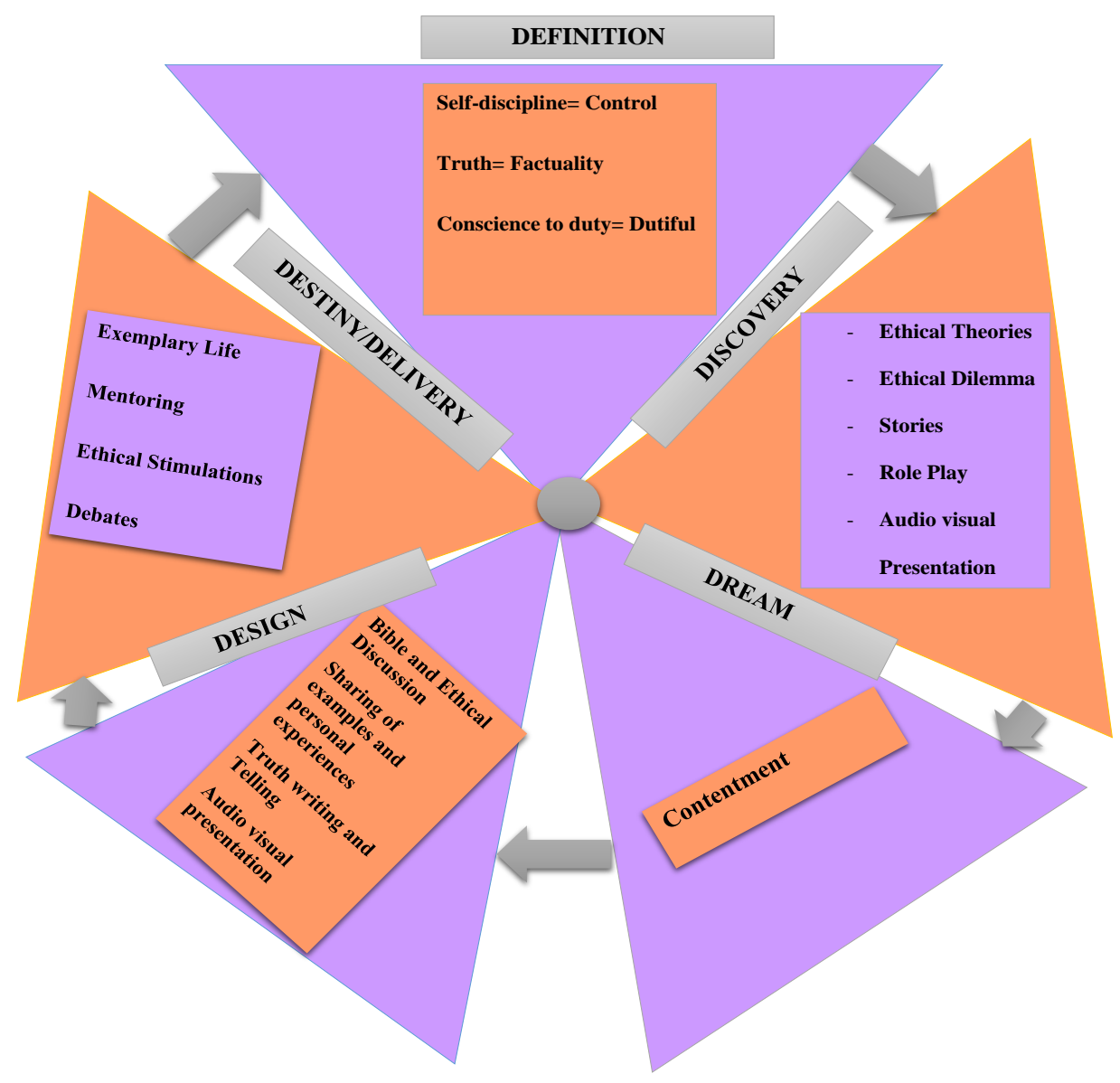

Figure 1. Roadmap for Creating Christian Behavior Change for Accounting Educators

The essence of Christian behavioral change in accounting education has values in the accounting profession. This lies in the fact that immoral behavior not only affects the individual career development but the entire profession, as well as the operations of business organizations, are negatively affected by moral non-adherence. In order to address the "Judas Iscariot syndrome" of misappropriation and wrong assumptions in the future among accountants and treasurers, the current accounting education model must inculcate self-discipline, truthfulness, and consciences to duty among the students. The study has produced a roadmap based on the appreciative inquiry to cause the Christian behavioral change. The dream for this change is to produce accountants and treasurers who are content with their resources - the design and delivery process of this dream, as shown in figure 1.

This process of Christian behavioral change for accounting educators is made circular as it is a never-ending approach. The study admits to the omniscience power of God and his grace towards Judas Iscariot. Jesus Christ did his best to influence Judas Iscariot positively. This implies that accounting educators must focus on having a positive impact on their students in order to affect "Judas Iscariot Syndrome" of misappropriation and wrong assumptions. The power of choice is with the student. This study recommends further investigation into the contentment approach for the accountant or treasurer.

\section{Reference}

Allom, V., Panetta, G., Mullan, B., \& Hagger, M. S. (2016). Self-report and behavioral approaches to the measurement 
of self-control: Are we assessing the same construct? Personality and Individual Differences, 90, 137-142. https://doi.org/10.1016/j.paid.2015.10.051

Appiah, J., \& Wa-Mbaleka, S. (2015). Integrating Faith and Learning in Distance Education in the Ghanaian Context. International Forum, 18(2), 83-104.

Brecht, B. (1966). Writing the truth; five difficulties. New York: Grove.

Collins, M. (1991). Adult education as vocation: a critical role for the adult educator. London: Routledge.

Crowe Clark Whitehill and the Centre for Counter Fraud Studies. (2017). The financial cost of fraud. Retrieved from https://www.accountant.nl/globalassets/accountant.nl/diversen/crowe-the-financial-cost-of-fraud-2017.pdf

English, L. M., \& Roy, C. (2015). Teaching the Truth: Social Justice and Social Class in Graduate School. Educational Considerations, 42(3), 22-28. https://doi.org/10.4148/0146-9282.1032

Fifolt, M., \& Lander, L. (2013). Cultivating Change Using Appreciative Inquiry. New Directions for Student Services, 2013(143), 19-30. https://doi.org/10.1002/ss.20056

Hagger, M. S., \& Hamilton, K. (2018). Grit and self-discipline as predictors of effort and academic attainment. British Journal of Educational Psychology. https://doi.org/10.31234/osf.io/k9zwe

Peprah, W. K. (2018). Predictive Relationships among the Elements of the Fraud Diamond Theory: The Perspective of Accountants. International Journal of Academic Research in Accounting, Finance, and Management Sciences, 8(3), 141-148.

Peprah, W. K., \& Ganu, J. (2018). The convergence of organizational culture, structure, and human capital performance: A conceptual analysis. Archives of Business Research, 6(5), 212-221. https://doi.org/10.14738/abr.65.4626

Pipim, S. K. (2018). Winning the fight against corruption: A sustainable path to Africa's Transformation. African Union Headquarters in Addis Ababa Ethiopia, January 28, 2018.

Sweet, P. (2018). Global cost of fraud tops £3 trillion. https://doi.org/10.1016/S1361-3723(18)30049-6

Tim, S., Agustina, L., \& Meyliana, M. (2017). A new classification of topics in behavioral accounting: current research direction from BRIA journal in the past ten years. Journal of Business and Retail Management Research, 11(3), 47-58.

Walters, S. L. (2016). Discipline vs. Self-Discipline, what's the difference? Retrieved from https://medium.com/@CMAHCA/discipline-vs-self-discipline-whats-the-difference-3371ada3151e

White, E. G. (1903). Education. Mountain View, CA: Pacific Press Publishing Association.

Wolfe, D., \& Hermanson, D. R. (2004). The fraud diamond considering four elements of fraud. The CPA Journal, 74(12), 38-42. https://doi.org/10.1016/S1361-3723(04)00065-X

Wood, A. (n.d). Kant on conscience. Retrieved from https://web.stanford.edu/ allenw/webpapers/KantOnConscience.pdf

Yigit, B. S. (2013). Auditor Independence: The Case of Arthur Andersen and Enron. International Conference on Economic and Social Studies, 10-11 May 2013, Sarajevo, 1(1).

\section{Copyrights}

Copyright for this article is retained by the author(s), with first publication rights granted to the journal.

This is an open-access article distributed under the terms and conditions of the Creative Commons Attribution license which permits unrestricted use, distribution, and reproduction in any medium, provided the original work is properly cited. 